\title{
A preliminary report on the production characters of three types of cattle in Ghana
}

\author{
G. MONTSMA
}

Formerly Lecturer in Animal Production, Faculty of Agriculture, University College of Ghana, Legon, Ghana

\begin{abstract}
Summary
Results of observations on production characters of cattle in Ghana (N'Dama, West African Shorthorn and Sokoto Gudali) are presented and discussed. It is concluded that at present the major limiting factors to beef and milk production are environmental, rather than genetical in nature.

With proper feeding and management practices milk yields can easily be doubled and reasonable growth rates obtained. Under practicable conditions the local type of West African Shorthorn is able to produce sufficient milk for calf and family needs.

As the types of cattle under observation are small in size and low in weight, comparison of production data with those of other types of cattle should be relative to body weight.
\end{abstract}

\section{Introduction}

The cattle population of Ghana is believed to be approximately one half million head. Over three-quarters of this total are found north of lat. $9^{\circ} \mathrm{N}$, the remainder being located in the southern savanna, around lat. $6^{\circ} \mathrm{N}$ and in scattered lagoon areas along the coast. Imports of cattle for slaughter amount to almost 100000 head per annum. This indicates that an expansion of the beef-cattle industry in this country is desirable from the point of view of national economy.

Very few data on production characters of cattle in Ghana and more generally, in West Africa, are available. In order to collect more information on this subject, a series of observations was started at the Agricultural Research Station Nungua, a research station of the Faculty of Agriculture, University of Ghana. This station is situated on the Accra Plains, which form part of the southern savanna area. Some of the more important factors studied are: birth weight, growth rate, age and weight at sexual maturity, age and weight at maturity, calving interval, age at first calving, milk yield, and the effects of different levels of feeding and management on these characters. As these observations started in 1957, only a few preliminary conclusions are possible.

\section{Material and methods}

Climatological data of the station may be summarized as follows: Mean annual rainfall 26 inches, but extremely erratic in nature, ranging from 17 to 47 inches. More than half of the total annual rainfall occurs in the period April to June, the main peak being in May-June; a second smaller peak occurs in October. Mean monthly

Received for publicaction 6th May, 1963. 
temperature $(15.00 \mathrm{hrs})$ ranges from $77^{\circ} \mathrm{F}$ in June to $87^{\circ} \mathrm{F}$ in March. Mean monthly relative humidity ranges from $60-80 \%$ at $15.00 \mathrm{hrs}$ and slightly higher at $09.00 \mathrm{hrs}$.

Three different types of cattle are available at the station, viz. West African Shorthorn, N'Dama and Sokoto Gudali. The first two are considered to be taurine-type, non-humped cattle, whereas the third is of Zebu origin. The West African Shorthorn on the station is of an intermediate type, as found on the Accra plains. They are larger and heavier than the West African Dwarf cattle, kept mainly in the lagoon areas; they are believed to contain a moderate amount of Zebu blood. The N'Dama type was imported from NW Ivory Coast, adjacent to Guinea and the Sokoto from North-western Nigeria.

Cattle are grazed day and night on the station and have access to silage during the worst part of the dry season. Mineral licks are as a rule available throughout the year. In order to build up the number of cattle at the station quickly, calving occurs throughout the year. Calves are weaned on a basis of age and body weight, the criteria being not necessarily identical for the three types. In future a restricted breeding season will be applied, facilitating management requirements.

Besides the three types already mentioned, a Jersey bull has been introduced for cross-breeding with the three local types. The first generation of crossbreds is now available, but has not yet reached the stage where the milk yield can be recorded. They are therefore not included in this report.

Calves are weighed and measured weekly up to six months of age, thereafter at monthly intervals up till one year of age and then quarterly until their second calf is born, or until they are disposed of in the case of bulls or bullocks.

\section{Results and discussion}

Relevant data, recorded during the past four years, are discussed under the following headings, which, however, inevitably overlap in some cases.

3.1. Body weight

3.2. Growth rate

3.3. Milk yield

3.4. Reproductive efficiency

3.5. Dentition and age

\subsection{Body weight}

A summary of body weights is presented in TABLE 1. It can be seen that the body weight of the N'Dama is comparable to that of the West African Shorthorn of the type present at the station. The West African Shorthorn is a very heterogenous type, with a body weight ranging from only slightly more than the West African Dwarf Shorthorn, reported as $365 \mathrm{lbs}$. for mature cows (MoNTSMA, 1959), to weights approaching those of West African types of Zebu, such as 727 lbs. for Sokoto cows in TABLE 1 and $750 \mathrm{lbs}$. for White Fulani cows (Joshi et al., 1957).

No absolute value should be attached to these body weights. This character is strongly affected by the plane of nutrition; trials at the station, in which different levels of supplementary concentrates were applied, indicate that body weights can easily be raised by 25 percent. None the less it is clear that the N'Dama and West African Shorthorn types are small-sized, light-weight animals, a fact to be borne in mind, when stocking rates, carcass weights and the like are considered. Comparison with 
G. MONTSMA

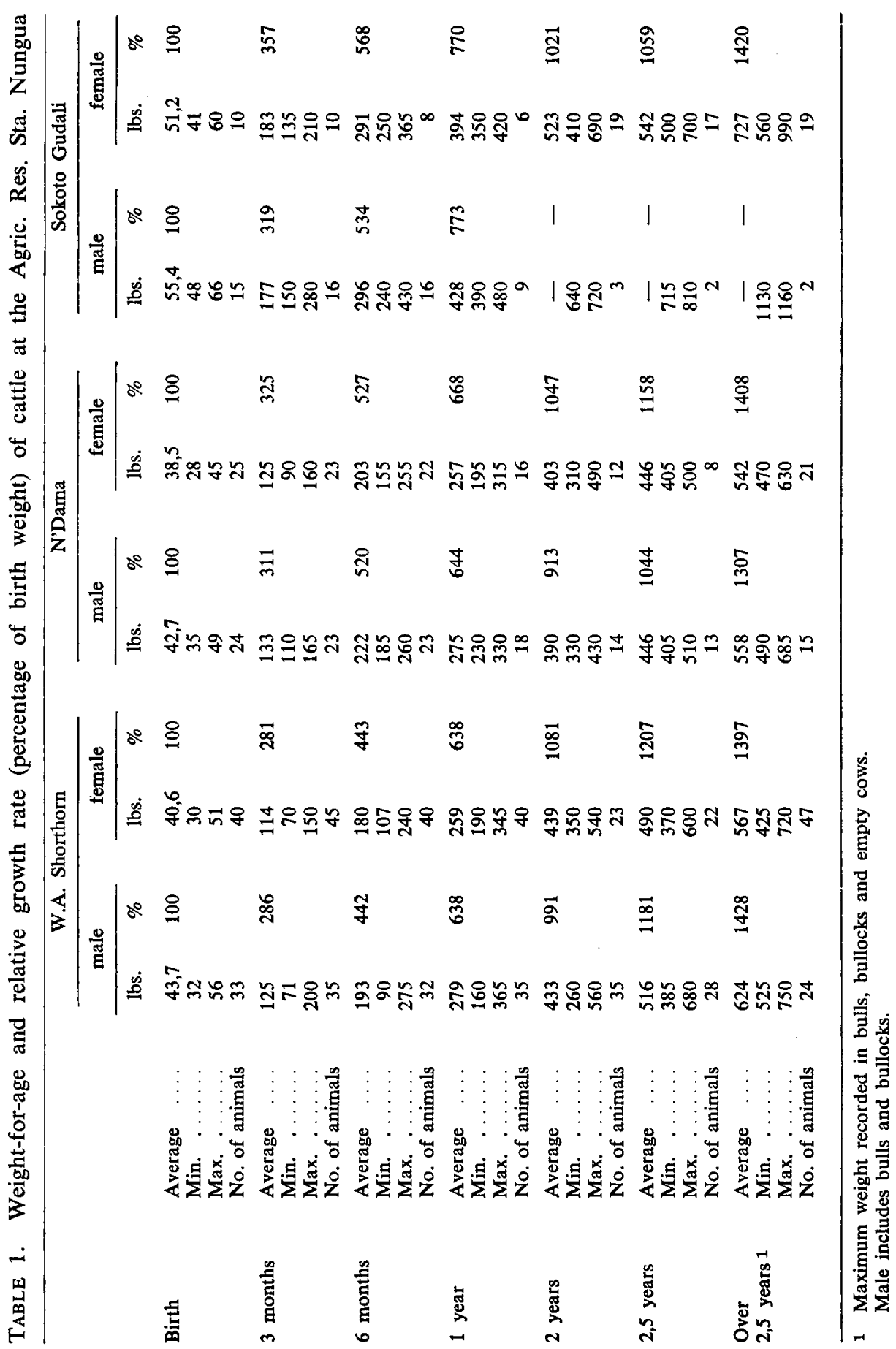


larger types is therefore only possible on a relative basis, such as beef production per acre or milk yield per 100 lbs. body weight.

As the Sokoto Gudali is a more recent acquisition at the station, not enough animals are available yet to provide reasonable average values. Several descriptions of the type have appeared recently (JosHI et al., 1957; FAULKNER and EPSTEIN, 1957).

\subsection{Growth rate}

TABLE 1 and FIG. $1-4$ give an indication of average growth rates of cattle on the station and also of the effects of level of nutrition and season of birth. Because of the low body weight of the N'Dama and West African Shorthorn types, body weights at different ages have been expressed in relation to birth weight.

It is emphasized again that these data have little absolute value. It can be seen in FIG. 4 for instance that better feeding will increase the growth rate by as much as $40-50 \%$. Fig. 3 indicates that the growth rate is closely related to the milk yield of the dam, and that a supply of concentrates to the suckling calf, though improving the growth rate, is an inadequate substitute for milk. It depends on the price of milk and the cost of concentrates, however, as to which method of rearing is most profitable. The salient point is that these calves showed a considerable response to both treatments. It should also be borne in mind that the benefits from adequate

FIG. 1. Birth weight in relation to season. Growth in the suckling period in relation to season (without supplementation). Note the peak in growth in June and a lower peak in September-October (rain)
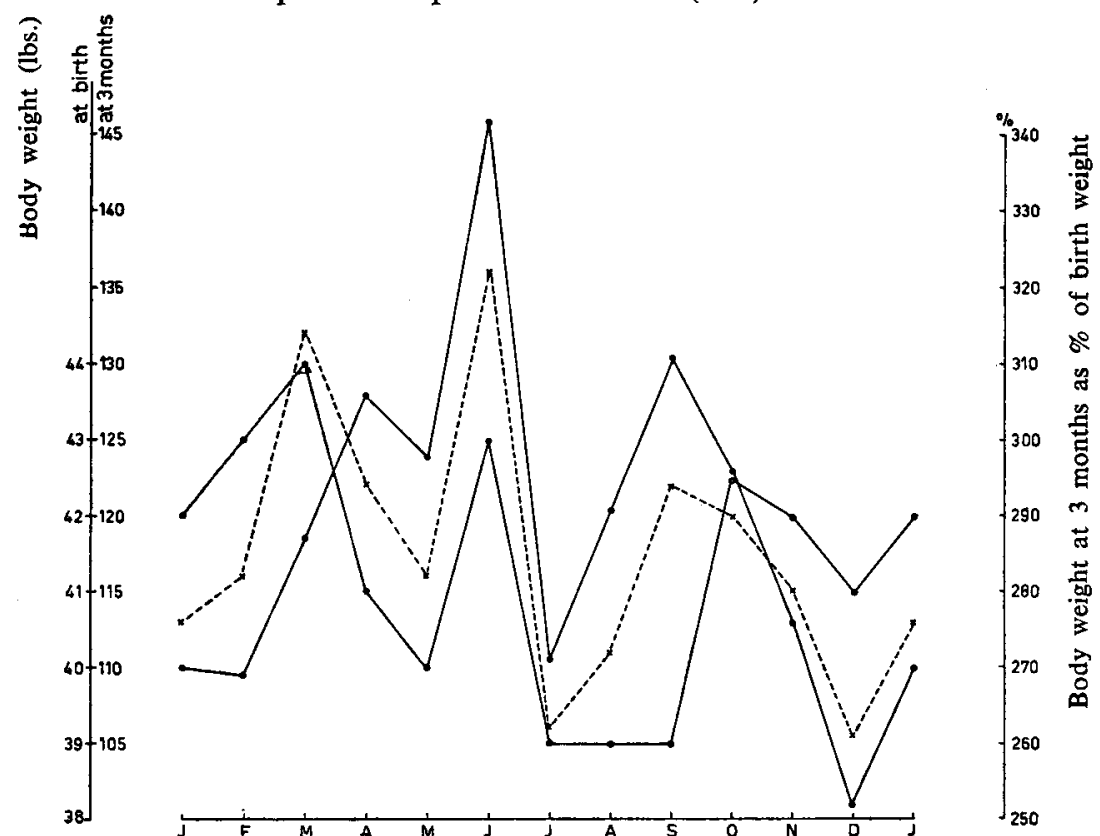

$\longrightarrow$ birth weight

..... 3-months weight

$\longrightarrow \%$ increase

Neth. J. agric. Sci., Vol. 11 (1963) No. 5 (November) 
FIG. 2. Effect of season on growth rate. Average of the three types; average of 90 animals, bulls, bullocks and heifers

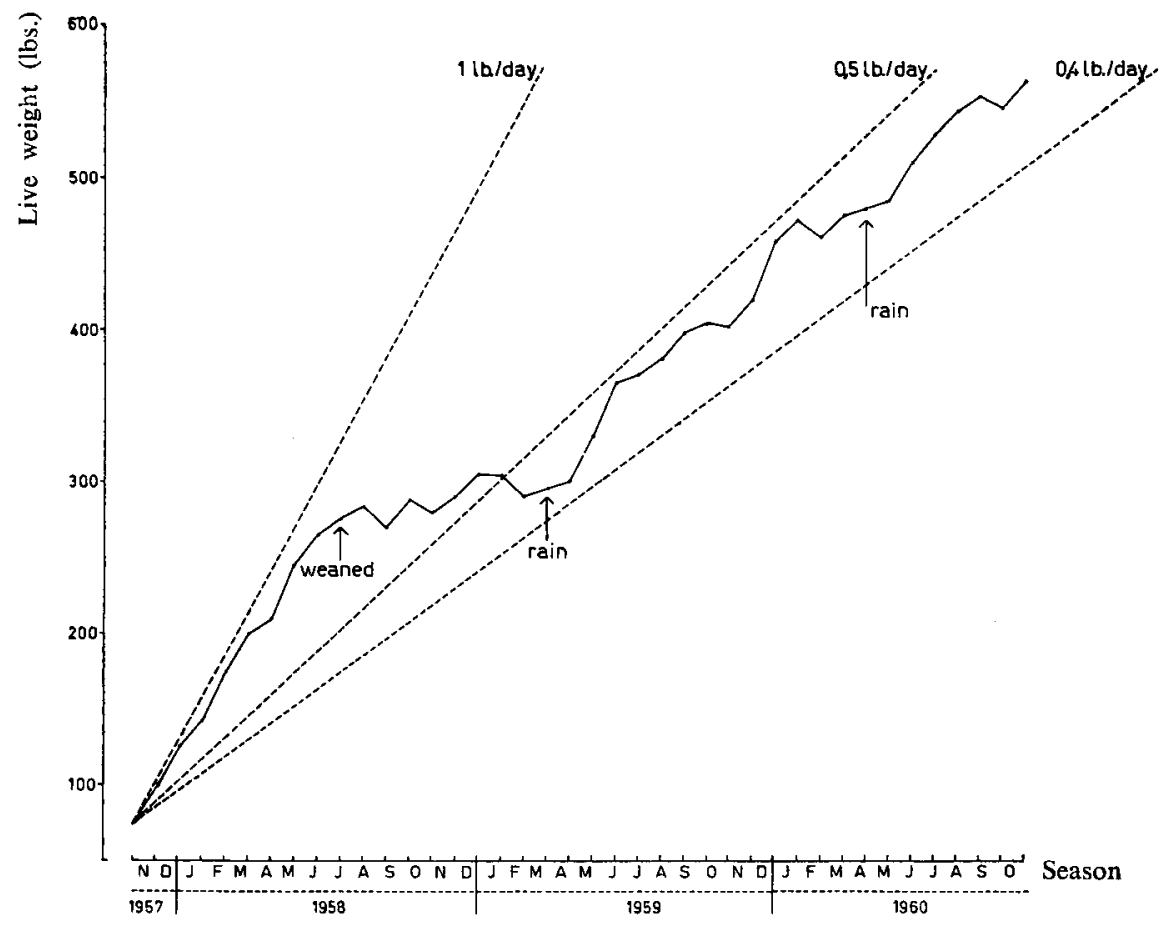

feeding during the suckling period are only fully achieved if the calves are well cared for after weaning.

During the suckling period a conversion efficiency of $12-13 \mathrm{lbs}$. body-weight increase per $100 \mathrm{lbs}$. of milk was recorded. This compares favourably with other breeds, including European types, where a ratio of $10 \mathrm{lbs}$. per $100 \mathrm{lbs}$. of milk is considered to be very reasonable.

FIG. 3 suggests also that conversion becomes less efficient with a high level of milk intake, particularly in the case of the Sokoto. This does not automatically imply that such high levels of milk intake are economically always less attractive. If a market for veal should become established, for instance, this form of meat production might show great promise. It should be noted, however, that conversion rates also decrease when milk intake becomes very low. It was found that conversion rates were on average $8 \%$ higher at an intake level of $10 \mathrm{lbs}$. per day than they were at a level of $6 \mathrm{lbs}$. per day. Put in another way, a $75 \%$ increase in milk yield resulted in a $7 \%$ increase in conversion rate. This indicates that the lower milk yield resulted in sub-optimal growth, whereas the higher milk yield was no longer a limiting factor in the growth of the calves.

Average body weights at eight months of 305,340 and $470 \mathrm{lbs}$. respectively for N'Dama, West African Shorthorn and Sokoto have been recorded under a betterthan-average feeding regime at the station. These data indicate that these types of 
Fig. 3. Relation between milk yield of dam and growth rate of calf. Effect of concentrate supplementation on milk yield and growth rate

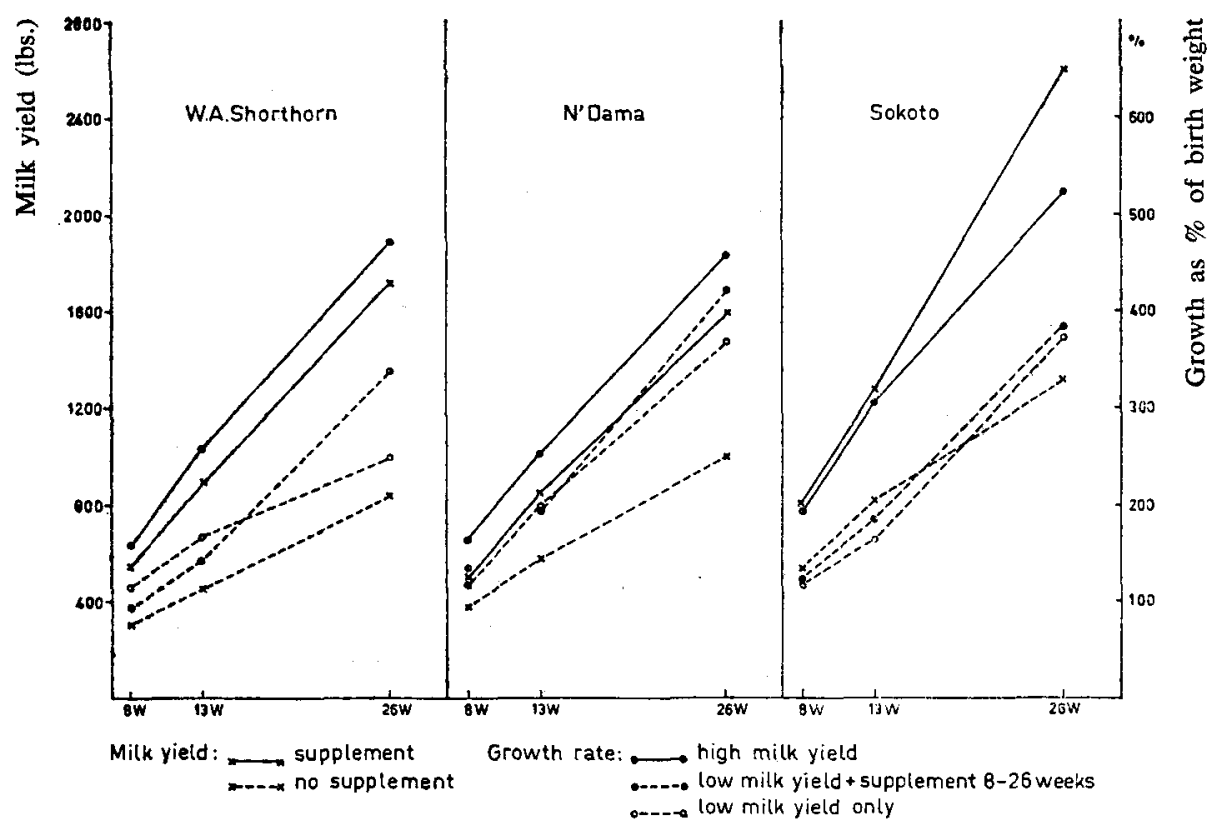

cattle are adaptable to more intensive forms of beef production. Maximum body weights at eight months were 340,360 and $550 \mathrm{Ibs}$. respectively for the three breeds, indicating a high degree of variation in these cattle, which have never been bred with a view to beef or milk production, and the level of beef production one might expect were this improved feeding regime to be combined with selective breeding. FIG. 1 indicates a slight seasonal variation in birth weight, which the author considers of little importance under present conditions. It is possible that a heavier calf will be able to consume more milk than a small calf, but this situation only occurs when the milk yield of the dam reaches a level higher than the calf's intake capacity. Although it is clear from FIG. 4 that growth rate is relatively higher in calves with a low birth weight, the effect of season of birth on growth rate is quantitatively more important.

Percentage growth rate in FIG. 1 is, irrespective of birth weight, higher in the rainy season than in the dry season. From April until October the growth curve is above the birth-weight curve, whereas from November till March it is below this curve. From FIG. 1 it would appear that the best growth rates are obtained from calves born from April to June. As only 107 calves born in four years were involved the absolute value of these curves should not be overestimated, particularly as dry-season conditions vary considerably from year to year. Moreover, calves born in May-June have to be weaned towards the beginning of the dry season, which is obviously not the most suitable time of year. Also, it is desirable for several reasons to restrict the calving season to approximately three months. Further research to assess the most favourable calving season is therefore one of the first requirements. 
Frg. 4. Average birth weight of the three Ghanese types compared with some other breeds, actual and relative to N'Dama. Percentage growth rate for the same breeds or types and effect of supplementation of dam in the Ghanese types

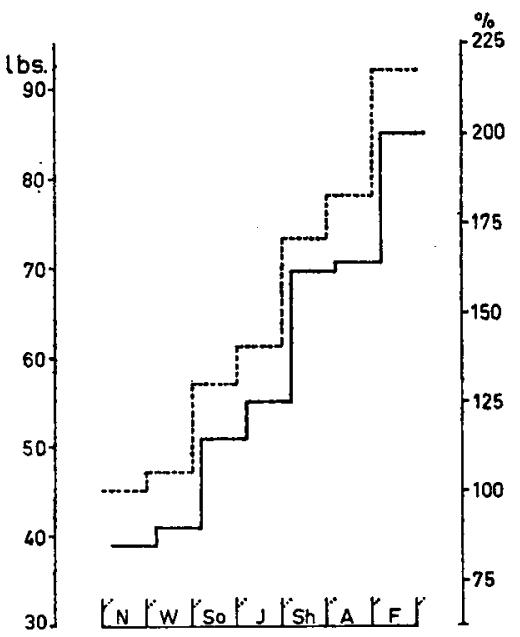

Actual

$\%$ of $N^{\prime}$ Dama 39 Lbs. $=100$

$\mathbf{N}=\mathbf{N}$ Dama

$\mathbf{W}=$ W.A. Shorthorn

So $=$ Sokoto

$$
\begin{aligned}
& \mathbf{J}=\text { Jersey } \\
& \text { Sh }=\text { Beef Shorthorn } \\
& \mathbf{A}=\text { Afrikaner } \\
& \mathbf{F}=\text { Friesian }
\end{aligned}
$$



If the above-mentioned body weights of 340,360 and 550 lbs. at eight months of age are expressed as percentages of birth weight, we arrive at maximum growth rates of 895,800 and $833 \%$ of birth weight, respectively for the three types. Hereford cattle on a private farm in Ohio, USA, are reported to weigh $431 \mathrm{lbs}$. at 230 days, i.e. $600 \%$ of their birth weight (SwIGER, 1961). On the station the suckling calves grow at a rate of nearly one $\mathrm{lb}$. per day. FIG. 2 indicates the importance of an adequate level of feeding in the post-weaning stage. Over-all weight gain of the cattle on the station is very disappointing, viz. just over $0,4 \mathrm{lbs}$. per day. This is mainly due to seasonal depressions. Further consideration of this curve suggests that the growth potential of these two types is reasonably high, since growth is considerable during the periods of abundance. Results of dry-season supplementation trials show the same trend. It is therefore considered possible to achieve a growth rate of approximately $0,8-1,0 \mathrm{lb}$. per day throughout the year, as far as the animals' growth potential is concerned. This implies that with adequate feeding throughout the year a slaughter animal can be produced in about half the time required without supplementation, i.e. a doubling of the rate of turn-over. More experimental evidence is, however, required. 


\subsection{Milk yield}

Few data on milk yield of West African types of cattle are available. (Joshi et al., 1957; Faulkner and Epstein, 1957; Faulkner and Brown, 1953; Douttressoulle, 1947 ; a.o.). The few data that are available, are usually obtained under experimental station conditions, and it is seldom clearly stated under what levels of feeding and management the production data were obtained. FIG. 5 gives an indication of milk yields obtained at the station under two different levels of nutrition. These milk yields were recorded by suckling the calves thrice daily for approximately twenty minutes

FIG. 5. Effect of supplementation on milk yield. Cows without supplementation were not milked after 6 months, as daily yield was too low

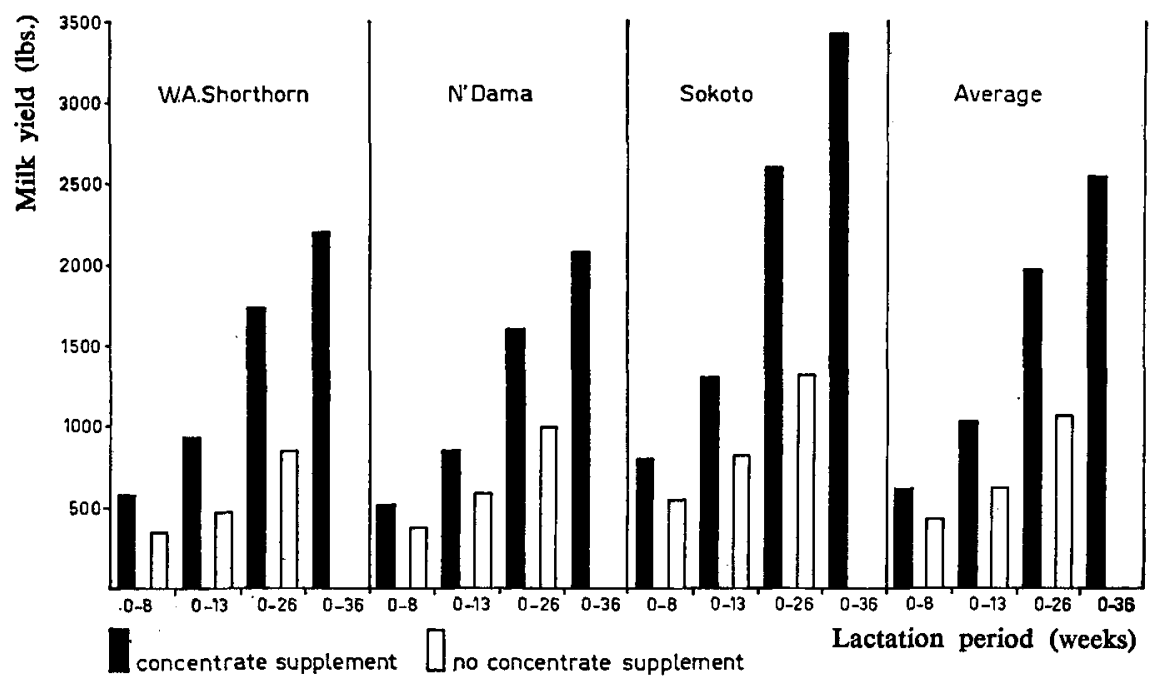

and weighing them before and after each suckling ${ }^{1}$. Six animals of each of the three types were involved in each trial. The lower yields occurred mainly in the dry season when the cows received only the station's dry-season ration (grazing if available, otherwise maize- or maize-and-bean silage and a very small amount of concentrates at the height of the dry season). The higher yields were recorded on cows that calved towards the end of the dry season. These cows were supplemented with four lbs. of a maize-groundnut cake mixture per day during the later stage of pregnancy and throughout the lactation period. Average, maximum and minimum yields are presented in TABLE 2. These data indicate that milk yields in trial I were low, compared with yields in temperate areas, but also that they could be substantially raised by means of better feeding (trial II). One should bear in mind that the average

1 As information on this procedure was very scanty when these trials were contemplated, it was decided to weigh the calves each day of the trial. After considering the results of these trials it appeared that reliable data for total milk yield can be obtained by weighing the calves on two consecutive days each week, or even by weighing one day a week. This information applies to the Nungua station and may need adaption if management conditions differ. Similar results are now reported from East Africa (LAMPKIN and LAMPKIN, 1960), and South Africa (HEYNS, 1960). 
Table 2. Milk yield in a 26-weeks lactation period in three cattle types at the Agric. Res. Sta. Nungua (see text)

\begin{tabular}{|c|c|c|c|c|c|c|c|}
\hline \multirow[t]{2}{*}{ Trial No. } & & \multicolumn{2}{|c|}{ N'Dama } & \multicolumn{2}{|c|}{ W.A. Shorthorn } & \multicolumn{2}{|c|}{ Sokoto Gudali } \\
\hline & & I & II & I & II & I & II \\
\hline $\begin{array}{l}\text { Minimum } \ldots \ldots \ldots \\
\text { Maximum } \ldots \ldots \ldots \\
\text { Average } \ldots \ldots \ldots\end{array}$ & $\begin{array}{l}\text { lbs. } \\
\text { lbs. } \\
\text { lbs. }\end{array}$ & $\begin{array}{r}924 \\
1128 \\
1015\end{array}$ & $\begin{array}{l}1422 \\
1864 \\
1594\end{array}$ & $\begin{array}{r}646 \\
1030 \\
846\end{array}$ & $\begin{array}{l}1640 \\
1879 \\
1724\end{array}$ & $\begin{array}{l}1137 \\
1585 \\
1330\end{array}$ & $\begin{array}{l}2054 \\
3233 \\
2599\end{array}$ \\
\hline $\begin{array}{l}\text { Difference } \\
\text { II-I (aver.) } \ldots \\
\text { (II-I) : I . . . }\end{array}$ & lbs. & \multicolumn{2}{|c|}{579} & \multicolumn{2}{|c|}{878} & \multicolumn{2}{|c|}{1269} \\
\hline
\end{tabular}

body weight of the types of cattle under consideration is also much lower than that of most temperate breeds. If in trial II the 252-day milk yields are expressed in relation to body weight, average yields per $100 \mathrm{lbs}$. body weight are 295, 300 and 335 lbs. respectively for N'Dama, West African Shorthorn and Sokoto. Maximum milk yields, expressed likewise, are 416,430 and $458 \mathrm{lbs}$. respectively. These latter yields are not extremely low, compared with a yield of $590 \mathrm{lbs}$. per $100 \mathrm{lbs}$. live weight, in a 305-day lactation period, for the British Dairy Shorthorn, or with $450 \mathrm{lbs}$. for the South Devon in Britain. (Farmer \& stockbreeder, 1957). When comparing these yields one should take into account that the lactation period of the Dairy Shorthorn is considerably longer, that the West African types have not been selected for milk production and that the environment in which the West African types have to perform is not conducive to high milk production. Further discussion of this point may be found elsewhere (MonTSMA, 1960, 1962).

In considering milk yields, it is necessary to indicate the purpose for which milk is to be produced, e.g. to rear the calf, to provide milk for local consumption, or for one or other form of dairy industry, since each level of production has its own particular requirements. For the rearing of a calf a milk yield of approximately $1000 \mathrm{lbs}$. in the case of N'Dama and Shorthorn, and $1500 \mathrm{lbs}$. in the case of the Sokoto may be considered adequate. But if a human family has to be supplied with fresh milk, an additional 1000 or 1500 lbs. would be required. Finally, a dairy industry would need yields of quite a different order - $6000 \mathrm{lbs}$. or more - in order to work economically.

The data presented suggest that the three West African types of cattle under consideration are able to meet the first two requirements if well managed and well fed. The West African Shorthorn is capable of yielding $2500 \mathrm{lbs}$. of milk under a nutritional regime which the author considers practicable in Ghana. Problems for a dairying enterprise in this country are too manifold to be discussed exhaustively within the scope of this paper. It is suggested, however, that the major difficulties might well arise at the processing rather than at the production stage. Furthermore, a high milk yield can only be achieved by means of first-class grazing facilities combined with considerable supplementation with concentrates, particularly under high atmospheric temperatures. Therefore, this form of production renders the animal more competitive for human foodstuffs.

\subsection{Reproductive efficiency}

Again little is known with regard to the reproductive efficiency of cattle in Ghana, 
but it is generally assumed to be low. A recent survey in Northern Ghana reports that in the district North Gonja cows have one calf every two years on average, and that in N.W. Ashanti only 30-35\% of the cows calve during the year (Anon, 1960; Hutchinson, 1960).

Several reasons can be suggested to explain this low reproductive rate. Firstly, an extreme phosphorus deficiency of the vegetation in large areas. Secondly, dry-season depressions because of lack of nutrients, particularly vitamin A. Thirdly, an inherent low level of fertility of the local stock.

\subsubsection{Calving interval}

FIG. 6 presents data on the calving percentages of the three 'breeds' at the A.R.S. Nungua, based on calving interval. Average calving percentages are 85,83 and $76 \%$ respectively for N'Dama, West African Shorthorn and Sokoto; these are equivalent to calving intervals of 14,$2 ; 14,5$ and 15,8 months respectively. These values are based on calvings recorded over five years in case of N'Dama and West African Shorthorn, but three years only in case of the Sokoto. It is expected that calving percentages will increase in future years, present figures having been lowered by inclusion of some very old animals, that are now being culled. In the case of the West African Shorthorn for instance the calving percentage rises to 99,8 if seven old and chronically barren cows are excluded. On average, $85 \%$ of all cows calve within 18 months and $36 \%$ within 13 months. In the N'Dama and West African Shorthorn types $45 \%$ of all cows calve within 13 months, i.e. a calving percentage of 92 .

In FIG. 7 calvings are arranged according to season. It can be seen that, although originally few calves were born in January-March, on average calvings are distributed fairly evenly over the year, if the breeding season is not restricted by man. For a good understanding of these trends it is necessary to realize that P-deficiency is unlikely on the station and that cows are supplemented during the dry season. As under these conditions calving rates are reasonable it is likely that low reproductive rates are largely due to environmental limitations.

\subsubsection{Age at first calving}

Average age at first calving on the station is at present three years for West African Shorthorn heifers, ranging from 2,3-3,8 years. Not enough calvings are as yet available in the two other breeds. This wide range in age at first calving occurs, because heifers are bred mainly on a basis of body weight, rather than age. West African Shorthorn and N'Dama heifers are mated when they reach a body weight of approximately $450 \mathrm{lbs}$., and Sokoto heifers at around $500 \mathrm{lbs}$. The age at which they reach 'mating weight' is mainly determined by the nutritional regime, i.e. milk yield of dam and post-weaning feeding conditions. This 'weight-for-age' criterium contains a certain measure of selection for adequate milk yield and earlier maturity.

Sexually, these types are rather early maturing. Calves have been noted to come on heat at eight months of age, if well fed, and one heifer by mistake conceived at eleven months of age. This means that it depends almost entirely on the regular availability of food, whether the heifer can be bred early or not. Present policy at the station is to breed heifers early, even at weights around $400 \mathrm{lbs}$., for N'Dama and West African Shorthorn, and not to breed them again for at least six months after the first calving. Results sofar suggest that the heifers develop better under this regime, provided no nutritional stress occurs. It is anticipated that heifers will 
G. MONTSMA

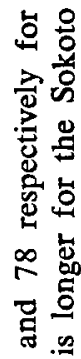

$\infty \overline{7}$

- $\stackrel{5}{\stackrel{5}{\leftrightarrows}}$

$\ddot{0}$

E

马ี

吃

它宗

总

표융

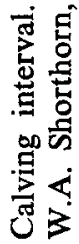

1


שT:P

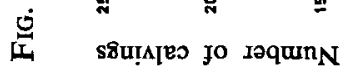


Fig. 7. Number of calvings in relation to season. Cumulative. Originally no calvings in the dry season. After dry-season supplementation a more even distribution

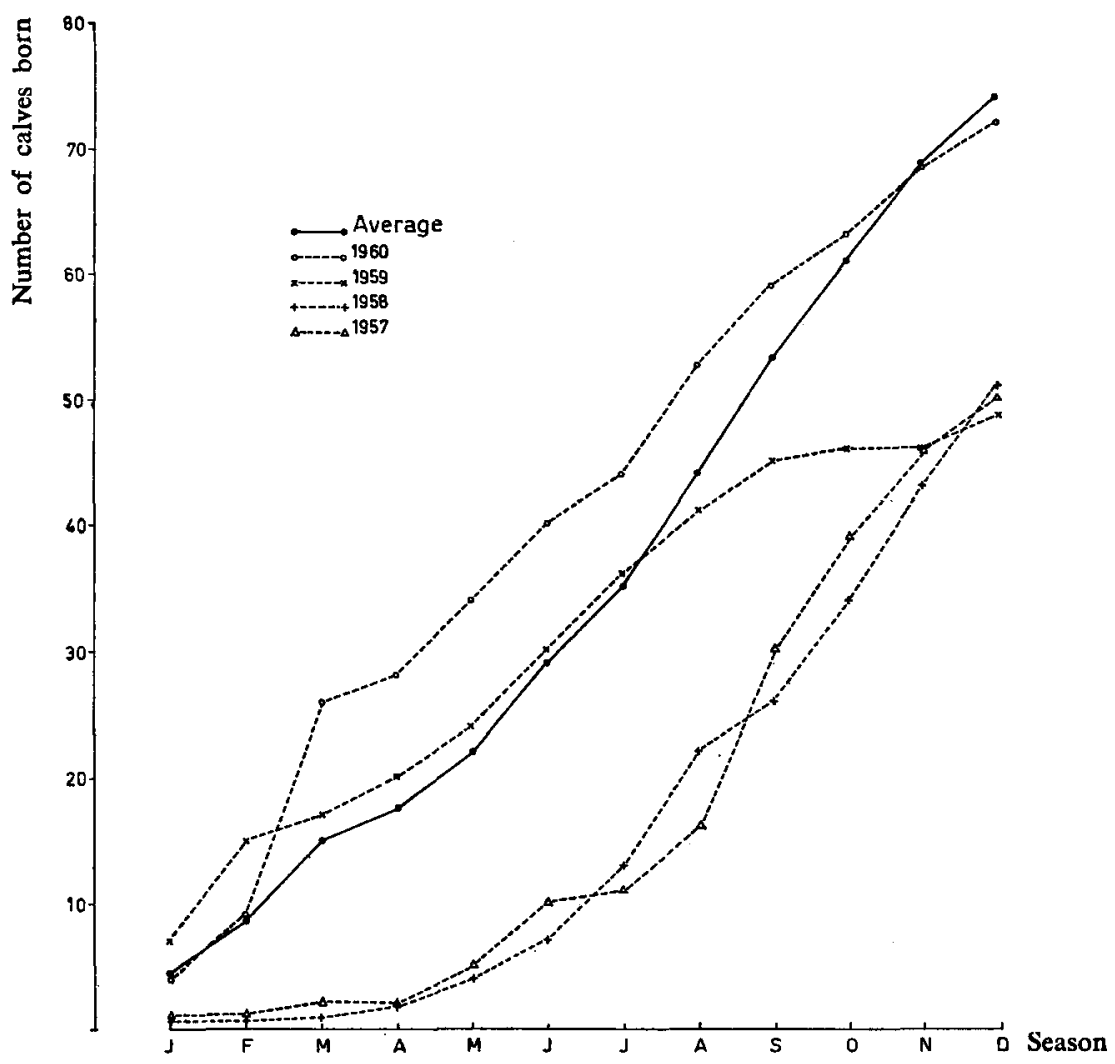

be capable of calving at $27-30$ months of age on average, without undue stress on their development and general well-being, provided an adequate food supply is available throughout the year. This, together with a calving interval of not more than one year would support a reasonable rate of turn-over.

\subsection{Dentition and age}

Environmental conditions appear to have a profound effect on several production characters, dealt with in previous sections. Data on dentition, recorded on the station so far, suggest that this character is very little affected by the environment. A few relevant data for N'Dama and West African Shorthorn types on the station are:

Birth : 2-8 temporary incisors

1 month : 8 , ,

2 years : first pair of permanent incisors erupt

2,5 years: second ", "

3 years : third " " " " " " "

3,8 years : fourth " " " " " " " 
Differences between the two types are negligible. Females are usually one to two months later. The above mentioned data are comparable with those for cattle in other countries (MILlER and West, 1956). A wide variation exists between individuals, however, which moreover is not consistent, i.e. the first pair of permanent incisors may appear as early as 1,8 years, whereas the second pair may erupt as late as 2,8 years in the same individual. Likewise the number of temporary incisors visible at birth bears no relation to the time of eruption of the permanent teeth. Correlation between body weight and age of eruption of the first pair of permanent incisors was found to be very low and not significant. Dentition is probably a better indication of chronological than of physiological age.

It was found that in a few cases several permanent incisors are cut before the milk teeth have disappeared. One heifer, for instance, was found to possess six permanent and five temporary incisors. The type of diet will possibly have influence on the time of eruption of the permanent incisors and in general on wear of teeth.

\section{General discussion}

The foregoing observations are not extensive enough to draw many definite conclusions.

Assuming that actual production is based on genetic potential and environmental conditions, data obtained suggest that under present circumstances the environment rather than the animal's productive potential is the major limitation to higher production. FAULKNER and BROWN (1953) come to a rather similar conclusion. Workers in several countries are presently engaged in assessing ratios between environmental and genetic limitations (WIENER, 1960; BRUMBY, 1959; LAMPKIN and LAMPKIN, 1960). As most of that work is being done on animals selected either for beef or for milk production, it is likely that the genetic part will play a less important part in their findings than it will in the West African types of cattle under observation, the latter being neither selected for milk nor for beef production and displaying a very large individual variation with regard to these characters.

Conditions as at present prevailing in large parts of Ghana's savanna areas require first of all a strong and hardy animal, capable of survival. Only when these conditions are improved, selection for better production, which is likely to entail the sacrifice of some of the animal's hardiness, will become possible.

As the present environment appears to be the major impediment to higher levels of production in the local types of cattle, adapted as they are to these conditions, it is unlikely that this same environment would be conducive to high production in imported stock of improved (refined) strains. Introduction of such improved types is therefore considered premature. Results obtained on experimental stations in Ghana and elsewhere may be encouraging, but they are at present and for many years to come unobtainable under farmer's conditions.

It seems therefore logical to improve the environment, particularly the feeding regime throughout the year, up to a level where the local types of cattle do no longer respond to further improvements, because of their genetic potential. At that level introduction of already improved types merits fresh consideration. This does not incur that no selection must be practised while the environment is being improved. Improvement of conditions and of stock should be gradual and concurrent, maintaining equilibrium between the two. 


\section{ACKNOWLEDGEMENTS}

Once more we wish to thank Mr. A. S. B. WiLson, Head of the Animal Production Division, Faculty of Agriculture, University (College) of Ghana, particularly for his critical correction of the English text. We are also grateful to the Management and staff of the Agric. Res. Sta. Nungua, and to $M$. N. Daniel for the laborious recording.

Anon

BRUMBY, P. J.

Doutressoulle, $G$.

FAULKNER, D. E., and J. D. BrowN

FaulKNer, D. E., and H. EPSTEIN

HEYNS, $\mathrm{H}$.

Hutchinson, R. A.

Joshi, N. R.,

E. A. McLaughlin and

R. W. PHILLIPS

LAMPKin, G. H., and K. LAMPKIN

Miller, W. C., and G. P. WEST

Montsma, G.

SNEDECOR, G. W., and W. G. Cochran

SWIGER, L. A.

Wiener, G.

\section{REFERENCES}

1960 United States operation mission in Ghana. Agricultural and livestock survey: N. Gonja and N.W. Ashanti. Min. Fd \& Agric., Accra.

1959 The relationship of inheritance and environment to herd production. N.Z. J. Agric. 99, 194.

1947 L'élevage en Afrique occidentale française. Larose, Paris.

1953 The improvement of cattle in British colonial territories in Africa. Col. Ad. Coun. Agric. Anim. H. For. Publ. No. 3, H.M.S.O. London.

1957 The indigenous cattle of the British Dependent Territories in Africa. Col. Ad. Coun. Agric. Anim. H. For. Publ. No. 5, H.M.S.O. London.

1960 The growth of the Afrikaner calf in relation to the production and composition of the milk of its dam. S.A. J. agric. Sci. 3, $3: 4$.

1961 Personal Communication Dept. Anim. H. Min. Fd \& Agric., Accra.

1957 Types and breeds of African cattle. FAO agric. stud. No. 37, Rome.

1960 Studies on the production of beef from zebu cattle in East Africa. J. agric. Sci. 55, 2.

1956 In: Black's Veterinary Dictionary. Black, London, 4th Ed.

1959 Some notes on the conformation of West African dwarf cattle. Trop. Agric. Trin. 36, 4: 299.

1960 Observations of milk yield, and calf growth and conversion rate, on three types of cattle in Ghana. Part I. Trop. Agric. Trin. 37, $4: 293$.

1962 Ibid. Part II. Effect of plane of nutrition. Trop. Agric. Trin. $39,2$.

1957 Statistical Methods. Ames, Iowa, U.S.A.

1961 Genetic and environmental influences on gain of beef cattle during various periods of life. J. anim. Sci. 20, $1: 183$.

1960 Factors influencing average milk yields of herds at two levels of production. Anim. Prod. 2, 117. 